\title{
Self-Reporting of Adverse Drug Reactions in Iraqi Hospitals: Patient's Perspectives
}

\author{
Kadhim Ali Kadhim \\ Department of Clinical Pharmacy, College of Pharmacy, Al-Mustansriya University, Baghdad, Iraq \\ Email: kadhimali_2011@yahoo.com
}

Received 10 November 2015; accepted 19 December 2015; published 22 December 2015

Copyright (C) 2015 by author and Scientific Research Publishing Inc.

This work is licensed under the Creative Commons Attribution International License (CC BY). http://creativecommons.org/licenses/by/4.0/

(c) (7) Open Access

\begin{abstract}
Background: Adverse drug reactions (ADRs) represent the important cause of morbidity and mortality that affect patients using drugs. Previous studies have clarified the knowledge and attitude toward ADRs reporting among healthcare providers, while studies toward awareness of patients are limited. Aim and Objective: To evaluate knowledge and attitude toward ADRs reporting among patients visiting general hospitals in Baghdad City. Methods: This observational study was conducted on randomly selected 300 patients at the out-patient setting of general hospitals in Baghdad. Demographic characteristics of participants were documented and questionnaire regarding knowledge and perceptions was given to fill up, and the data were analyzed using descriptive statistics. Results: Demographic analysis showed that $55 \%$ of patients were males, $62 \%$ of them were from rural areas, and only $34 \%$ were college graduates. Regarding knowledge about ADRs, $73.3 \%$ patients were aware about ADRs and $37 \%$ had experienced ADRs in past. None of the respondents were aware of ADR reporting center. Regarding perceptions toward ADR, 84.2\% agreed to report ADR in future and $90 \%$ respondents believed that ADR reporting may strengthen the patient safety. According to $61 \%$ of patients, patient education program is the best way to educate them regarding ADR. Conclusion: Educational interventions are highly recommended to improve awareness among patients regarding the validity of ADRs reporting.
\end{abstract}

\section{Keywords}

ADRs, Self-Reporting, General Hospital, Reporting System

\section{Introduction}

Adverse drug reactions (ADR) can be defined as the noxious response to drug action that occurs during administration of normal doses for the prophylaxis, diagnosis and treatment of diseases [1]. To achieve a high standard 
public health, the effective and safe consumption of drugs and other health care products must be carefully watched and monitored through a well-organized and effective pharmacovigilance system [2]. Broad spectrum knowledge about drug safety is limited at the time of approval for marketing, and the voluntary reporting of ADRs to the health care authorities is one of the important approaches for careful monitoring of post-marketing safety of drugs [3]. Moreover, ADRs are considered as the major cause behind patient related morbidity and mortality [4], and mostly lead to a high rate of hospital admission that may reach a value of $6.5 \%$, in addition to considerable socioeconomic impact directly related to the high cost of drug related hospital admissions [5]. Accordingly, reporting of ADRs is considered to be vital process in maintaining and achieving a safe drug use. An effective pharmacovigilance practice plays an important role in the reduction of ADRs; thus the progress of such approach is critical for effective clinical use of drugs and health care products [6]. Spontaneous reporting of ADRs is one of the basic requirements of the effective pharmacovigilance system to monitor drug-induced unwanted actions [7]. This approach is simple, not expensive and enables generation of database regarding the potential problems associated with drug use and identification of ADRs [8]; however, the strength of this approach is correlated to the actual reporting rate by the health care providers [9]. Establishing of national databases regarding ADRs is not a new trend in clinical practice, and already has initiated by health care professionals in collaboration with the WHO since 1968 through the Drug Monitoring Program that supports the report of ADRs [10]; however, the problems related under-reporting of many serious and fatal reactions were continuously addressed by the WHO [11], and unexpected ADRs were rarely reported. This project aims to assess knowledge and perception toward ADRs among patients visiting general-care hospitals, and to shed a light on the importance of patient's perceptions about ADRs reporting approach.

\section{Methods}

This observational, cross-sectional, questionnaire-based study was conducted at 4 specialized out-patients clinics at different general hospitals within Baghdad City during August to December 2014. A pre-validated 14-item questionnaire that includes open and close-ended questions related to the patients' knowledge and perception toward ADRs was composed after referring previous studies conducted about consumer pharmacovigilance [12] [13]. The questionnaire was modified according to local community requirements and translated into Arabic language, and validated before approval by the research ethics committee of the College of Pharmacy, Almustansriya University. The requirement for written informed consent was waived as the questionnaire was made anonymous. Eighty patients from each area (i.e., waiting area near Medicine outpatient department, outpatient Laboratory collection, and Pharmacy of the Hospital) were selected randomly on daily basis for $1 \mathrm{~h}$. Inpatients and pediatric patients were excluded. Study purpose and research hypothesis were explained to patients, and the respondents were educated about the procedure of filling the questionnaire and enough time allowed to them to fill up. The questionnaire includes:

- Are you educated about the expected ADRs of your medications by health professionals?

- Do you know whether prescribed can cause adverse effects?

- Have you ever demonstrated any kind of ADRs during treatment with drugs?

- Have you ever seen any side effect after taking drugs in other person?

- Have you ever told your physician or the pharmacist about the ADRs you practiced?

- Are you taking any herbal drugs other than those prescribed to you?

- Are you aware there is an ADR reporting center at the hospitals?

- If there is an ADR reporting center in your hospital, would you like to report?

- What do you do when any ADR occurs to you due to drug use?

- In your opinion who is qualified to recognize and report ADR?

- According to you what could be the purpose of ADR reporting?

- Do you think the ADR reporting system is beneficial to the public?

- According to you, which is the best way to educate patients regarding ADR reporting?

- If you are educated about ADRs, who is the source of knowledge among health care providers?

Basic demographic data such as gender, age, educational qualification, socioeconomic state, smoking habits and alcohol consumption and whether the respondent was originally from a rural or urban area were noted. The data were expressed as mean \pm SD and percentages. The data collected from the questionnaire was analyzed using SPSS software. $x^{2}$-Test was used to evaluate the association between variables. A $P$-value of less than 0.05 indicated statistical significance. 


\section{Results}

In the present study, 320 patients were interviewed and 300 of them accepted to participate by giving verbal informed consent. The age group ranged from 20 to 65 years with a mean age of $38.2 \pm 8.6$ years. Of the participants, 165 (55\%) were males and 135 (45\%) were females. Sixty-two percent of the patients (186) belonged to rural areas, whereas 114 (38\%) were from urban areas. Sixty (20\%) participants were primary school graduates, 138 (46\%) were secondary school graduates, and the remaining 102 (34\%) were college graduates (Table 1). Regarding the knowledge about ADRs, 220 (73.3\%) patients were aware about the possibility of ADR occurrence during treatment with drugs; of them, $82 \%$ were from urban areas whereas $68 \%$ were from rural areas. The difference between awareness of participants from urban and rural areas was statistically significant $(P=$ 0.02) (Figure 1). Figure 2 shows that statistically significant increase was reported regarding trend in awareness according to the educational levels $(P<0.05)$. Meanwhile, no significant difference was observed in the awareness of patients from different age groups and gender. Regarding the answers of participants about ADRs, 52 (17\%) patients had answered about what they understand by the term ADRs, and majority of them gave example of skin manifestations. Regarding the history of ADRs, 112 (37\%) patients had past experience with ADRs after taking drugs, and 69 (23\%) patients had observed ADRs in others. Regarding the use of herbal drugs or alternative medicine, $42 \%$ of the participants were continuously taking drugs obtained from natural sources, in addition to their prescribed traditional drugs; meanwhile, only 146 (48.6\%) patients had some knowledge about alternative medicines. None of the patients were aware that alternative medicine can also cause ADR. None of the participants were aware that there was an ADR reporting facilities available at the hospital they refer, and they did

Table 1. Demographic characteristic of the study sample $(n=300)$.

\begin{tabular}{|c|c|}
\hline Parameter & Results \\
\hline Age (years; mean \pm SD) & $38.2 \pm 8.6$ \\
\hline \multicolumn{2}{|l|}{ Gender $n(\%)$} \\
\hline Male & $165(55 \%)$ \\
\hline Female & $135(45 \%)$ \\
\hline \multicolumn{2}{|l|}{ Educational qualifications $n$ (\%) } \\
\hline Primary school graduates & $60(20 \%)$ \\
\hline Secondary school graduates & $138(46 \%)$ \\
\hline College graduates & $102(34 \%)$ \\
\hline \multicolumn{2}{|l|}{ Socioeconomic status $n$ (\%) } \\
\hline Low & 69 (23\%) \\
\hline Medium & $153(51 \%)$ \\
\hline Adequate & 78 (26\%) \\
\hline \multicolumn{2}{|l|}{ Geographical location $n$ (\%) } \\
\hline Rural & $186(62 \%)$ \\
\hline Urban & $114(38 \%)$ \\
\hline \multicolumn{2}{|l|}{ Cigarette smoking $n$ (\%) } \\
\hline Smokers & $102(34 \%)$ \\
\hline Non-smokers & $198(66 \%)$ \\
\hline \multicolumn{2}{|l|}{ Alcohol consumption $n$ (\%) } \\
\hline Drinkers & $12(4 \%)$ \\
\hline Non-drinkers & 288 (96\%) \\
\hline
\end{tabular}




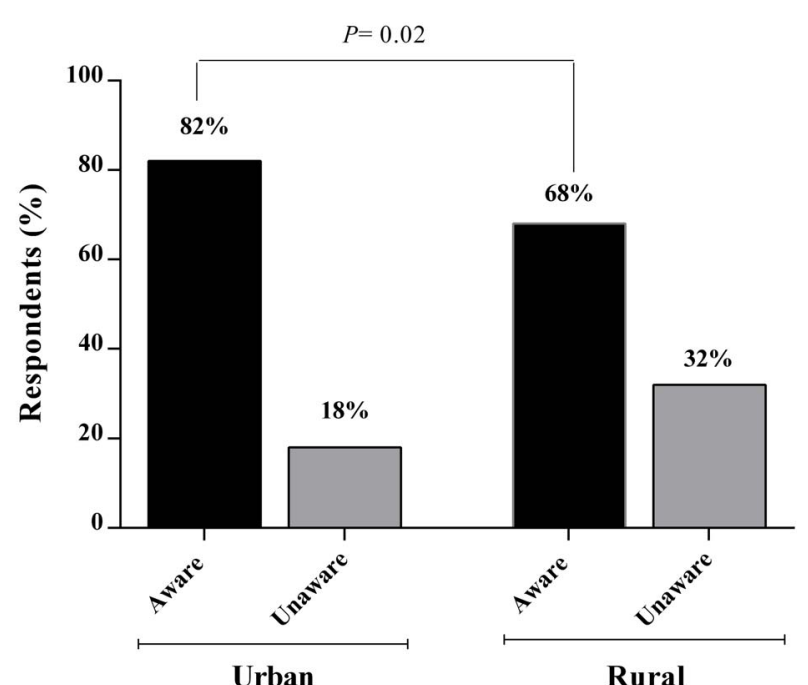

Figure 1. Patients' awareness: whether medicines can cause ADRs distributed according to geographical location.

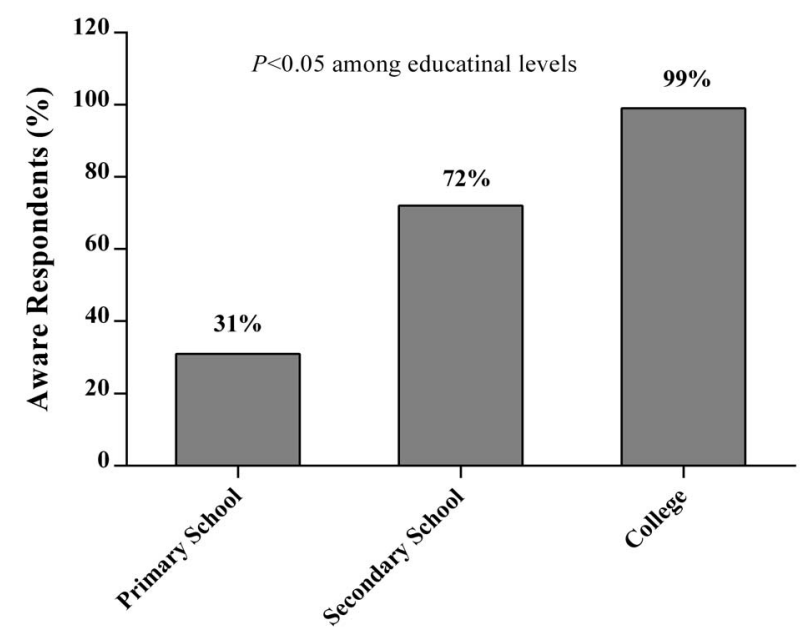

Figure 2. Patients' awareness related to their education level: whether drugs can cause adverse reactions.

not report any ADRs during the time of using medications, even for chronic use. All (100\%) participants declared that they should contact the hospitals on occurrence of an ADR during the use of their medications. The majority of participants agreed that physicians are highly qualified to recognize and report ADRs, and the aim of this approach is mainly related to improve patient safety; meanwhile, patient education is considered as the best way to increase patient awareness about ADRs (Tables 2-4). Among the participants, 270 (90\%) patients believed that reporting ADRs is beneficial for all peoples. Regarding perceptions toward ADRs, 253 (84.2\%) patients accepted to report ADRs at their hospitals or to the health care providers in future when they come across the ADRs. Moreover, the majority of patients, who are already educated about the possible ADRs of their medications, mentioned the physician as the major source of ADRs knowledge.

\section{Discussion}

The majority of participated patients were found aware about the concept of ADRs reporting, and this issue was significantly greater in urban area residents; this finding was in tune with that reported by Jha et al. [13]. Moreover, the trend of ADRs awareness was increased with the elevation of educational levels of the patients; however, the participants did not report or address their experience of ADRs at any time during treatment to any one 
Table 2. Patients' opinion about the person qualified to recognize and report an ADR.

\begin{tabular}{|cc}
\hline In your opinion who is qualified to recognize and report ADR? & Response \\
\hline Physicians & $225(75 \%)$ \\
Nurses & $10(3.4 \%)$ \\
Pharmacists & $45(15 \%)$ \\
Patients & $5(1.6 \%)$ \\
All the above & $15(5 \%)$ \\
\hline
\end{tabular}

Table 3. Patients' perception about the aim of ADRs reporting.

\begin{tabular}{cc}
\hline Patients' perception about the aim of ADRs reporting & Response \\
\hline To improve patient safety & $159(53 \%)$ \\
To prevent recurrence of ADRs in the same patient & $84(28 \%)$ \\
To help the physician for good prescribing practice & $54(18 \%)$ \\
Just to address the regulatory authorities & $3(1 \%)$ \\
\hline
\end{tabular}

Table 4. Patients' perception about the best way to educate patients about ADRs reporting.

\begin{tabular}{cc}
\hline What is the best way to educate patients about ADRs reporting? & Response \\
\hline Patient education by health professionals & $183(61 \%)$ \\
Awareness campaign through media & $69(23 \%)$ \\
By reading drug leaflet & $36(12 \%)$ \\
Published articles regarding ADRs & $12(4 \%)$ \\
\hline
\end{tabular}

of the medical staff or health care authorities. The current finding was in tune with that reported by Elkalmi et al. [14] in Malaysian patients. The present study showed that the interviewed patients might lack the proper knowledge about the ADRs of their prescribed drugs. It has been reported previously that that poor knowledge about ADRs did not exclude identification of such events because of either unexpected nature of the timing or nature of symptoms [12]; accordingly, the health care providers share the responsibility to give adequate information about the prescribed drugs and inform their patients to report any unexpected symptoms to them. Regarding ADRs awareness of the participants, the results of the present study can be considered as valid outcome, since there was no impact for external factors like media reports or previous consultation from an expert in this field; so the data reflect the believe of the patients on ADRs issue. The majority of participants believed that reporting ADRs can improve safety of treatment and limit further recurrence of ADRs, and most of them have the attitude toward this practice if they are well educated to so. Similar results in this respect were reported elsewhere [15]. In the present study, the results indicated that studied patients did not have enough idea about the ADRs reporting centers in the health care institutions, and they should be informed about how to report ADRs and the committees to which these findings should be reported. The current finding was in tune with that reported previously by others, where healthcare professionals and drug consumers did not have prior idea about the reference centers in their healthcare facilities [16] [17]. Many studies were conducted regarding self-reporting of ADRs, with emphasis on the requirement for establishing a separate ADRs reporting system for the consumers [18]. Accordingly, pioneer centers were established in many countries with variable degree of satisfaction, and the most important limiting factor in this regard was the education of patients about the concept of ADRs [19]. The advantage of ADRs reporting by the consumers refers to direct reporting from the person affected (instead of reporting within or via a health care setting) and considered as a matter of consumer rights; this approach was established and clarified by the WHO [20]. Despite the raised concerns with this kind of direct ADRs reporting, many studies have suggested that patients' reports instead can add value to those reported by the healthcare pro- 
fessional by identifying potential new ADRs [21] [22] and may potentially contribute to reliable pharmacovigilance systems [23]. Moreover, subjective toxicities are at high risk of being under-reported by physicians, and the WHO states that patients' reporting could be vital to both help the patient to receive optimal proper treatment and also to safeguard public health programs [24]. In the current study, $61 \%$ of the participants stated that patient education programs about ADR reporting are the preferred approach to increase their awareness about ADRs reporting. In future, public awareness of the ADR reporting system should be recognized and, and its importance for medical professionals, as well as patients, making it essential that ADR report information be disseminated to medical institutions and that related advertising campaigns are initiated for the general public.

\section{Conclusion}

There is a strong need to make patients be aware about the ADRs reporting, and educational interventions should be established to improve awareness among patients regarding importance of ADRs reporting.

\section{Acknowledgements}

The author thanks Al-Mustansriya University for supporting the project.

\section{Conflict of Interest}

The author declares no conflict of interest.

\section{References}

[1] World Health Organization (1972) International Drug Monitoring: The Role of National Centers. Technical Report Series No. 498, World Health Organization, Geneva.

[2] Kalaiselvan, V., Mishra, P. and Singh, G.N. (2014) Helpline Facility to Assist Reporting of Adverse Drug Reactions in India. WHO South East Asia Journal of Public Health, 3, 194.

[3] Ishiguro, C., Hall, M., Neyarapally, G.A. and Dal Pan, G. (2012) Post-Market Drug Safety Evidence Sources: An Analysis of FDA Drug Safety Communications. Pharmacoepidemiology and Drug Safety, 21, 1134-1136. http://dx.doi.org/10.1002/pds.3317

[4] Watson, R. (2012) New EU Drug Safety Committee Ends National Reporting of Drug Reactions. BMJ, 345, e4690. http://dx.doi.org/10.1136/bmj.e4690

[5] Pirmohamed, M., James, S., Meakin, S., Green, C., Scott, A.K., Walley, T.J., Farrar, K., Park, B.K. and Breckenridge, A.M. (2004) Adverse Drug Reactions as Cause of Admission to Hospital: Prospective Analysis of 18,820 Patients. BMJ, 329, 15-19. http://dx.doi.org/10.1136/bmj.329.7456.15

[6] Sarker, A., Ginn, R., Nikfarjam, A., O’Connor, K., Smith, K., Jayaraman, S., et al. (2015) Utilizing Social Media Data for Pharmacovigilance: A Review. Journal of Biomedical Informatics, 54, $202-212$. http://dx.doi.org/10.1016/j.jbi.2015.02.004

[7] Harmark, L., van Hunsel, F. and Grundmark, B. (2015) ADR Reporting by the General Public: Lessons Learnt from the Dutch and Swedish Systems. Drug Safety, 38, 337-347. http://dx.doi.org/10.1007/s40264-015-0264-1

[8] Robertson, J. and Newby, D.A. (2013) Low Awareness of Adverse Drug Reaction Reporting Systems: A Consumer Survey. MJA, 199, 684-686. http://dx.doi.org/10.5694/mja13.10069

[9] Passier, A., ten Napel, M., van Grootheest, K. and van Puijenbroek, E. (2009) Reporting of Adverse Drug Reactions by General Practitioners. A Questionnaire-Based Study in the Netherlands. Drug Safety, 32, 851-858. http://dx.doi.org/10.2165/11314490-000000000-00000

[10] World Health Organization (2002) The Importance of Pharmacovigilance: An Essential Tool. WHO, Geneva.

[11] World Health Organization (2002) Safety of Medicines-A Guide to Detecting and Reporting of Adverse Drug Reactions. Why Health Professionals Need to Take Action. WHO, Geneva.

[12] Hughes, L., Whittlesea, C. and Luscombe, D. (2002) Patients' Knowledge and Perceptions of the Side-Effects of OTC Medication. Journal of Clinical Pharmacy and Therapeutics, 27, 243-248. http://dx.doi.org/10.1046/j.1365-2710.2002.00416.x

[13] Jha, N., Ratthore, D.S., Shankar, P.R. and Gyawali, S. (2014) Pharmacovigilance Knowledge among Patients at a Teaching Hospital in Lalitpur District, Nepal. Journal of Clinical and Diagnostic Research, 8, 32-34. http://dx.doi.org/10.7860/jcdr/2014/7378.4097 
[14] Elkalmi, R., Hassali, M.A., Al-Lela, O.Q., Jawad Awadh, A.I., Al-Shami, A.K. and Jamshed, S.Q. (2013) Adverse Drug Reactions Reporting: Knowledge and Opinion of General Public in Penang, Malaysia. Journal of Pharmacy and Bioallied Sciences, 5, 224-228. http://dx.doi.org/10.4103/0975-7406.116824

[15] Blenkinsopp, A., Wilkie, P., Wang, M. and Routledge, P.A. (2006) Patient Reporting of Suspected Adverse Drug Reactions: A Review of Published Literature and International Experience. British Journal of Clinical Pharmacology, 63, 148-156. http://dx.doi.org/10.1111/j.1365-2125.2006.02746.x

[16] Hartigan-Go, K. (2002) Developing a Pharmacovigilance System in the Philippines, a Country of Diverse Culture and Strong Traditional Medicine Background. Toxicology, 181-182, 103-107. http://dx.doi.org/10.1016/S0300-483X(02)00263-9

[17] Vessal, G., Mardani, Z. and Mollai, M. (2009) Knowledge, Attitudes, and Perceptions of Pharmacists to Adverse Drug Reaction Reporting in Iran. Pharmacy World \& Science, 31, 183-187. http://dx.doi.org/10.1007/s11096-008-9276-6

[18] Ahmed, A.M., Izham, I.M. and Subish, P. (2010) Importance of Consumer Pharmacovigilance System in Developing Countries: A Case of Malaysia. Journal of Clinical and Diagnostic Research, 4, 2929-2935.

[19] Palaian, S., Alshakka, M. and Izham, M. (2010) Developing a Consumer Reporting Program in Malaysia: A Novel Initiative to Improve Pharmacovigilance. Pharmacy World \& Science, 32, 2-6. http://dx.doi.org/10.1007/s11096-009-9342-8

[20] World Health Organization (2012) Safety Monitoring of Medicinal Products: Reporting System for the General Public. http://www.who.int/medicines/areas/quality safety/safety efficacy/qas safetymonitoringmp/en/

[21] Avery, A.J., Anderson, C., Bond, C.M., Fortnum, H., Gifford, A., Hannaford, P.C., et al. (2011) Evaluation of Patient Reporting of Adverse Drug Reactions to the UK "Yellow Card Scheme": Literature Review, Descriptive and Qualitative Analyses, and Questionnaire Surveys. Health Technology Assessment, 15, 1-4. http://dx.doi.org/10.3310/hta15200

[22] Harmark, L., van Hunsel, F. and Grundmark, B. (2015) ADR Reporting by the General Public: Lessons Learnt from the Dutch and Swedish Systems. Drug Safety, 38, 337-347. http://dx.doi.org/10.1007/s40264-015-0264-1

[23] Margraff, F. and Bertram, D. (2014) Adverse Drug Reaction Reporting by Patients: An Overview of Fifty Countries. Drug Safety, 37, 409-419. http://dx.doi.org/10.1007/s40264-014-0162-y

[24] World Health Organization (2006) The Safety of Medicines in Public Health Programs: Pharmacovigilance an Essential Tool. WHO, Geneva. 